\title{
The Effect of Habitus and Capitals on Adoption Behavior of E-Commerce Information System: An Investigation of Digital Immigrants
}

\author{
Huifen Wang, Junping Wang \\ School of Management, Jinan University, Guangzhou, China \\ Email: twhf@163.com, penerpener@126.com
}

How to cite this paper: Wang, H.F. and Wang, J.P. (2017) The Effect of Habitus and Capitals on Adoption Behavior of ECommerce Information System: An Investigation of Digital Immigrants. Open Journal of Social Sciences, 5, 159-170. https://doi.org/10.4236/jss.2017.54015

Received: March 15, 2017

Accepted: April 25, 2017

Published: April 28, 2017

Copyright ( 92017 by authors and Scientific Research Publishing Inc. This work is licensed under the Creative Commons Attribution International License (CC BY 4.0).

http://creativecommons.org/licenses/by/4.0/

\begin{abstract}
With the rapid development of e-commerce, more and more digital immigrants actively participate in online shopping. However, some may be more skilled in using e-commerce information system (e-commerce IS), while others still meet some barriers doing so. Thus, it is interesting to investigate the e-commerce IS adoption behavior of digital immigrants. To understand the critical resources that contribute to the different behaviors between the digital immigrants, we attempt to operationalize the capital perspective, drew on Bourdieu's practice theory and propose a research model to investigate: 1) the forms of capital and habitus for using e-commerce IS; 2) what is the relationship between digital immigrant's capital, habitus and e-commerce IS adoption behavior. Based on the data collected from 334 digital immigrants in China, we empirically test the proposed model. To ensure the validity and reliability of the instrument, factor analysis and reliability test were conducted. The results of multiple regression analysis demonstrate the significant effects of habitus and capitals on digital immigrants' e-commerce IS adoption, especially the intrinsic motivation and propensity to informatization dimension of habitus, the social influence and social support dimension of social capital. Implications of the findings as well as limitations of the study and directions for future research are also discussed.
\end{abstract}

\section{Keywords}

Bourdieu, Capital, Habitus, Digital Immigrants, E-Commerce IS, Adoption Behavior

\section{Introduction}

Online shopping is becoming an integral part of people's live in China. The rise 
of electronic commercial enterprise and online retailers, along with the growth of smartphones and laptops, has encouraged the rapid development of e-commerce. Statistics show that, in 2015, the amount of Chinese online shopper reached 413 million with a growth rate of $14.3 \%$.

At the same time, the scale of the Chinese elderly Internet users is also growing. According to the China Internet Network Information Centre (CNNIC) [1], Internet usage of Chinese users from 40 to 59 years old is steadily increasing. This group directly falls into the category of the digital immigrants, who learnt to use computers at some stage during their adult life. Moreover, the growth has been gradually shifting to the middle-aged and elderly. An increasing number of digital immigrants participate in online shopping, just like the young generation. It is an opportunity for electronic commercial enterprise to develop and maintain this new group of consumer.

However, some digital immigrants appear to be quite skillful in using e-commerce IS, they are familiar with the operating procedures and functions of the online shopping sites, mobile apps and so on, they bought things online all by their own, while another group of digital immigrants seem to experience strong barriers and obstacles, they may turn to the others for help. This disparity presents an interesting opportunity to investigate the e-commerce IS adoption behavior of digital immigrants.

In previous information system (IS) research, as for e-commerce IS adoption/acceptance, most of the scholars adopted the classic information technology adoption model, and developed a variety of new factors to extend the basic model [2], which failed to deeply explain the relationships among the influencing factors. In addition, few studies have focused on the middle-aged and elderly group, that is, the digital immigrants.

Some IS scholars have proposed that information system usage is affected by an individual's cultural, social, and material resources [3]. In addition, consumer behavior literature identifies psychological disposition or motivation as a differentiating resource for human behaviors in general. Along these lines, we drew on Bourdieu's practice theory and identify the four key concepts (habitus, cultural capital, social capital, and economic capital) of this theory as the key forms of capital for using e-commerce IS that contribute to the different IS adoption behaviors.

The purpose of this study is therefore to explore the E-commerce IS adoption behavior of Chinese digital immigrants. Hence, our first research question is what forms of capital should be considered by e-commercial enterprises to stimulate digital immigrant' adoption of e-commerce IS, and the second research question is what is the relationship between digital immigrant's capital, habitus and e-commerce IS adoption behavior.

Our research has some theoretical and empirical contributions. The conceptual framework helps enrich the existing theories of e-commerce IS research and generation research. The empirical findings may yield some implications for ecommerce IS designers, managers, and information service professionals for at- 
tracting more and more Chinese digital immigrants to adopt e-commerce IS.

The paper is organized as follows. In Section 2, we provide a literature review of related studies. The research model and hypotheses are proposed in Section 3. Then Section 4 describes the research methodology used in this study, followed by the results of data analysis in Section 5. Finally, in Section 6 we discuss our results, and present implications, limitations. In Section 7, we make a conclusion.

\section{Theoretical Background}

\subsection{Digital Immigrant}

Digital natives and digital immigrants are two terms coined by Marc Prensky in a 2001 essay [4]. Digital natives are those who have grown up in a digital world where the use of information and communications technologies is pervasive and ubiquitous. Digital immigrants are those who learnt to use computers at some stage during their adult life [5]. The novel classification provides an interesting perspective from which to examine the type and role of IS/IT users and attract some attention from both practitioners and scholars.

Based on our literature review, commonly there are two thresholds defining digital immigrants: age and accessibility. In this study, we still use the age as a threshold to define the Chinese digital immigrants for its convenience in sampling and filtering. Here we use two factual data as the bases for judgments. First, it is 1987 that China firstly had an access to the Internet, and it is 1994 that China officially got access to the Internet. Second, it is 1995 that personal computer and mobile phone entered the Chinese market. In that case, those who were born before 1975, at least 12 years before the first access to the internet and at least 20 years before the first personal computers and mobile phones were on sale can be regarded as the digital immigrants, since they spent their childhood without any access to internet, and they never had any experience using a PC or mobile phone before their adulthood. They were not born in the digital era but gradually adopted the digital technologies or adapted to various digital arte facts in their later days. Therefore, in this paper, the participants who are above 40 years old (and including 40) are the targets of our study.

\subsection{Bourdieu's Practice Theory}

Bourdieu's theory of practice focuses on the role of social practice in shaping, and being shaped by the linked concepts of "field," "habitus," and "capital." [6]. With these concepts, scholars will be better able to deepen their understanding of the forces that shape actors' behavior.

Habitus, a signature concept of Bourdieu, refers to a set of dispositions and embodied behaviors derived from the unconscious internalization of the social structure [6] [7]. Since habitus explains why agents from different social groups show different pattern of social behavior and attitude, which leads to different social outcomes, it explains the mechanism of stable reproduction of social structure [8]. 
Bourdieu's capital theory mainly includes cultural capital, social capital and economic capital. Cultural capital comprises the knowledge, skills, tastes, preferences, and possessions that give advantage (or disadvantage) in the system of relations [9]. These aspects of culture and knowledge can take different forms, from the aesthetics, tastes, and ways of speaking acquired through socialization, to the institutionalized knowledge and skills that are acquired through formal training and qualification. Once acquired, these institutionalized forms of cultural capital also have symbolic potential to convey issues of reputation.

Social capital highlights the importance of the mutual relationships and acquaintances that reinforce or advance an actor's relative position of power within the field [9], and includes interpersonal relationships and the resources embedded in those relationships [10]. Economic capital relates to the possession and control of financial capital, intellectual property, and shares, for example, and is directly and immediately convertible into money [11].

Some IS scholars have proposed that information system usage is affected by an individual's cultural, social, and material resources. In addition, consumer behavior literature identifies psychological disposition or motivation as a differentiating resource for human behaviors in general. Along these lines, we identify the four key concept (habitus, cultural capital, social capital, and economic capital) of Bourdieu's practice theory as the key forms of capital for using e-commerce IS that contribute to the different IS usage behaviors.

\section{Research Model and Hypotheses}

Figure 1 depicts the research model. The logic for the models is based on the notion that the availability of critical resources affects individuals' general behaviors. As shown in Figure 1, we expect habitus, cultural capital, social capital, economic capital and their sub-dimensions to be important determinants of the e-commerce adoption behavior.

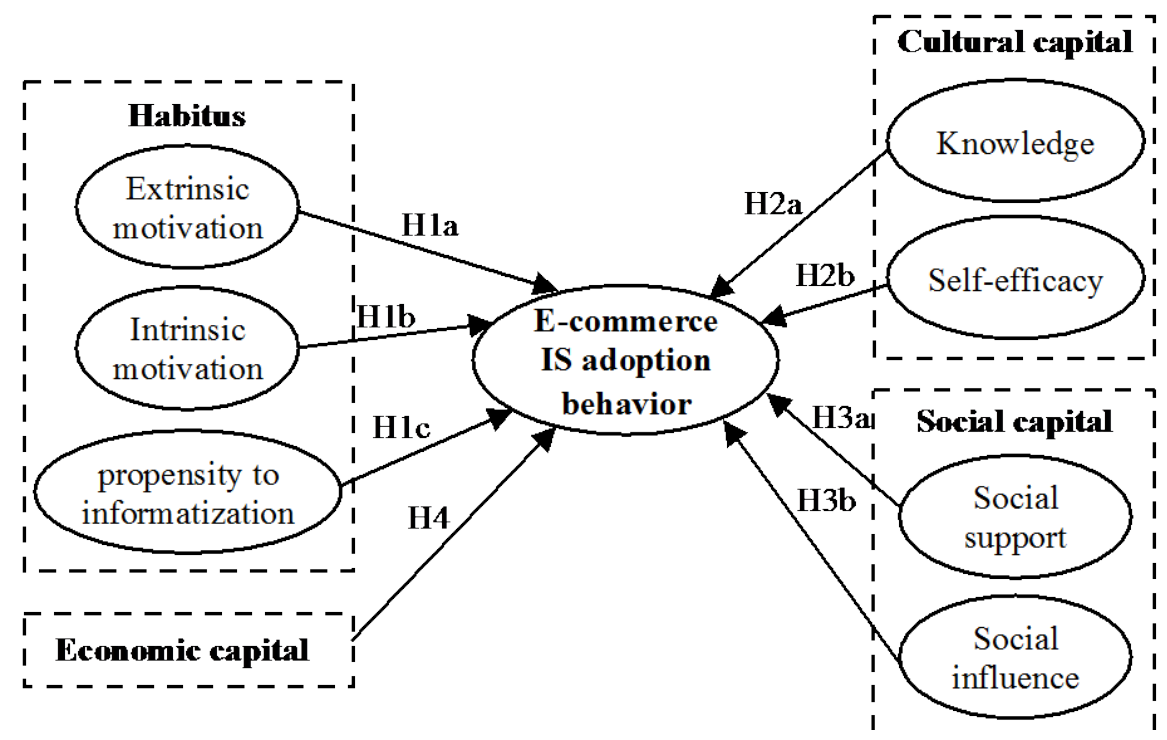

Figure 1. Research model. 


\subsection{Habitus}

Kvasny and Keil found that habitus, which describes an individual's disposition, attitude, and expected benefits about using IS, affects actual practices [12]. Henry suggested that individual dispositions are important psychological resources [13]. To capture this psychological capital, we adapt the habitus concept to our investigative context and define it as an individual's disposition toward using e-commerce IS. Scholars have suggested that individual motivation or orientation toward using an IS has a critical effect on actual behavior. DeHaan reported that positive/negative motivations are mental drivers/barriers for IS adoption [14]. Therefore, to capture an individual's utilitarian and hedonic evaluations of IS usage, we identify extrinsic motivation and intrinsic motivation [15] as constituent properties of habitus. In addition, as embodied aspect of IS habitus, propensity to informatization will also impact IS usage, thus, we propensity to informatization as the third dimension of habitus. The above discussions lead to the following research propositions:

H1a: The extrinsic motivation dimension of habitus will have a positive effect on e-commerce IS adoption behavior.

H1b: The intrinsic motivation dimension of habitus will have a positive effect on e-commerce IS adoption behavior.

H1c: The propensity to informatization dimension of habitus will have a positive effect on e-commerce IS adoption behavior.

\subsection{Cultural Capital}

In this study, cultural capital is defined as the embodied competencies needed to use an e-commerce IS. The skills, knowledge, and capabilities embodied within individuals are internal resources that enable human activities. Bourdieu conceives that cultural capital (CC) can manifest itself in three forms, including 1) objectified CC, such as pictures and books; 2) institutional CC, such as educational credentials; and 3) embodied CC, or the internal competencies needed to appropriate, understand, and use cultural artifacts.

Knowledge has been suggested to be a necessary resource for understanding and operating an innovation. Rogers argued that lack of adequate operational knowledge might not only discourage initial acceptance but also hinder the actual application of an innovation [16]. Meanwhile, self-efficacy describes the belief in one's ability to perform a behavior. Without sufficient self-efficacy, or confidence, even a person with adequate knowledge may not achieve intended outcomes. Therefore, some view self-efficacy as a person's "believed competencies" for task performance [17]. Although cultural capital is often regarded as knowledge or skills, it has been extended to include individual confidence. Similarly, IS scholars have also conceptualized knowledge and self-efficacy as two different aspects of user competence. In our study, we also identify knowledge and self-efficacy as the sub-dimensions of cultural capital. The above discussions lead to the following research propositions:

H2a: The knowledge dimension of cultural capital will have a positive effect 
on e-commerce IS adoption behavior.

$\mathrm{H} 2 \mathrm{~b}$ : The self-efficacy dimension of cultural capital will have a positive effect on e-commerce IS adoption behavior.

\subsection{Social Capital}

In our context, social capital refers to the resources from one's social networks for using e-commerce IS. IS researchers have offered similar concepts that capture productive social resources for innovative behaviors. De Haan, for example, indicated that such social resources as access to acquaintances in one's social setting who can offer advice or support would be instrumental for IS use. It is also widely accepted that important referents' behavioral expectations, or subjective norms, will influence one's IS use [18] With this backdrop, we focus on two social capital factors that appear to be especially relevant to our context: support from acquaintances (social support) and perceived expectations from family, relatives, peers, and friends (social influence). Also, having access to acquaintances that can provide information and knowledge about IS usage represents not only instrumental assistance but also emotional support that can encourage adoption. The above discussions lead to the following research propositions:

$\mathrm{H} 3 \mathrm{a}$ : The social support dimension of social capital will have a positive effect on e-commerce IS adoption behavior.

$\mathrm{H} 3 \mathrm{~b}$ : The social influence dimension of social capital will have a positive effect on e-commerce IS adoption behavior.

\subsection{Economic Capital}

In this study, economic capital refers to the monetary means to acquire and access e-commerce IS. Obviously, people with high socioeconomic status tend to possess more information technology access, contact and use experience, and thus more likely to use e-commerce IS. The above discussions lead to the following research propositions:

H4: Economic capital will have a positive effect on e-commerce IS adoption behavior.

\section{Research Methodology}

To test the proposed model, we used the survey method for data collection, and examined our hypotheses by using multiple regression analysis on 334 useful data. The unit of analysis was the individual.

\subsection{Measurement}

The test scales for habitus, cultural capital, and social capital, and their dimension used in our survey were all adapted from the previous literatures. These variables were measured using a five-point Likert scale ranging from "strongly disagree" to "strongly agree. As to economic capital, the annual household income of the respondents was used to measure economic capital. To measure the dependent variable, e-commerce IS adoption behavior, the following question 
was asked in the survey: "how do you participate in online shopping in your daily life?" Three categories were coded for the analysis: 3 = I know how to operate e-commerce IS and always buy things online all by myself, 2 = I always need to turn for help during the whole online shopping process, 1 = I always ask others to buy things online for me and never use an e-commerce IS. Finally, 21 survey questions were used to measure the constructs, other questions were used to capture the profile of survey respondents, including age, gender, educational level, internet experience, frequency of online-shopping and so on.

\subsection{Sample and Data Collection}

The questionnaire was translated from English to Chinese and then back-translated from Chinese to English by certified professional translators to ensure the integrity of the constructs. Before deploying the main survey instrument, we invited 15 digital immigrants who have online shopping experience to conduct a pilot study in order to ensure that their understanding of the meaning of the items was consistent with the constructs being used in this study. Some minor modifications were made based on their feedbacks. The revised questionnaire was then used for the formal online survey. Then, We collaborated with a professional data collection service provider, which can directly send our online questionnaires to those who meet our sample requirements: 1) He/she was born before 1975, that is, above 40 yeas old. 2) He/she has been involved in online shopping. About 1.5 mouths later, a total of 361 digital immigrants completed the survey, and 334 of their data are valid. The demographic details of these respondents are described in Table 1.

Table 1. Descriptive statistics of the whole sample.

\begin{tabular}{|c|c|c|c|c|c|c|c|}
\hline Dimension & Category & Frequency & Percentage & Dimension & Category & Frequency & Percentage \\
\hline \multirow[t]{2}{*}{ Gender } & Male & 205 & 61.4 & \multirow{7}{*}{ Occupation } & $\begin{array}{c}\text { Civil } \\
\text { servants }\end{array}$ & 47 & 14.1 \\
\hline & Female & 129 & 38.6 & & Managers & 123 & 36.8 \\
\hline \multirow{5}{*}{ Age } & $41-45$ & 112 & 33.5 & & $\begin{array}{l}\text { Private } \\
\text { owners }\end{array}$ & 18 & 5.4 \\
\hline & $46-50$ & 141 & 42.2 & & Specialist & 32 & 9.6 \\
\hline & $51-55$ & 44 & 13.2 & & $\begin{array}{c}\text { Office } \\
\text { workers }\end{array}$ & 23 & 6.9 \\
\hline & $56-60$ & 23 & 6.9 & & others & 91 & 27.2 \\
\hline & $>60$ & 14 & 4.2 & & $<1$ year & 4 & 1.2 \\
\hline \multirow{4}{*}{ Education } & Senior high school & 56 & 16.8 & \multirow{4}{*}{$\begin{array}{c}\text { Internet } \\
\text { experience }\end{array}$} & 1 - 3 year & 38 & 11.4 \\
\hline & Junior college & 135 & 40.4 & & $3-5$ year & 154 & 46.1 \\
\hline & Bachelor's degree & 123 & 36.8 & & $5-10$ year & 106 & 31.7 \\
\hline & Master's degree & 20 & 6 & & $>10$ year & 32 & 9.6 \\
\hline \multirow{5}{*}{$\begin{array}{c}\text { Annual } \\
\text { household } \\
\text { income }\end{array}$} & $<80,000$ & 30 & 9 & \multirow{5}{*}{$\begin{array}{c}\text { Online } \\
\text { shopping } \\
\text { experience }\end{array}$} & $<1$ year & 30 & 9 \\
\hline & $8,000-200,000$ & 157 & 47 & & 1 - 2 year & 140 & 41.9 \\
\hline & $200,000-300,000$ & 112 & 33.5 & & $2-3$ year & 104 & 31.1 \\
\hline & $300,000-1000,000$ & 25 & 7.5 & & 3 - 5 year & 41 & 12.3 \\
\hline & $>1000000$ & 10 & 3 & & $>5$ year & 19 & 5.7 \\
\hline
\end{tabular}




\section{Data Analysis}

The data analysis was conducted in two phases. In the first phase, we established the validity of the scales used, through construct reliability. In the second phase, we performed multiple regression analysis. We use SPSS 20.0 to analyze the data.

\subsection{Reliability and Validity Analysis}

As to reliability analysis, Cronbach's $\alpha$ is utilized for testing internal consistency of questionnaire. The result shows that, Cronbach's $\alpha$ coefficient of habitus test scale, cultural capital, and social capital is $0.895,0.813$ and 0.871 , respectively, which are all above 0.7 , so the questionnaire in this study has a relatively good reliability.

Factor analysis method can be used for testing validity. KMO and Bartlett Spherical Test can be conducted firstly before factor analysis. In our study, the results show that KMO values of habitus test scale, cultural capital, and social capital is $0.876,0.802$ and 0.707 , respectively, which are all above 0.7 . In addition, significant probability of Bartlett spherical test is $\mathrm{P}<0.01$, namely the result is significant. It is in line with the research standard available for factor analysis.

Then, factor analysis method is used for respectively analyzing factors of all indicators, and we use principal component analysis. Factor load of each variable measurement indicator on the research scalar is calculated, most factor loads of each measurement indicator are above 0.5 , which is in line with the validity test requirements. In addition, total explanation degree of the variable measurement indicators on research variable is also tested in this study, they are all above $70 \%$. It indicates that research scalar measurement indicator have been rationally set, which can be further researched and analyzed.

\subsection{Data Analysis}

In the study, multiple regressions are utilized for analyzing and discovering how respective variables act on dependent variables, and influence on dependent variables. Multiple regressions were estimated to model the relationships between respondents' adoption behavior of e-commerce IS and their habitus, cultural capital, social capital, economic capital

According to our statistics, as shown in Table 2, the value of adjusted $\mathrm{R}$ square is 0.605 , which indicates that the degree of explanations of the chosen independent variables reached $60.5 \%$, exceeded the recommended level of $30 \%$, so it can conclude that the chosen independent variable for the model is reliable.

Table 3 presents the results of Anova, the value of $\mathrm{F}$ is 64.777, and Sig. is less than 0.01 , which indicated that the fitting result of the model is satisfied, and our model is reasonable. As shown in Table 4, the standardized coefficients of extrinsic motivation is -0.053 , the value of $t$ is -1.023 , the absolute value is less than 1.96 , so it can conclude that the extrinsic motivation dimension of habitus have no significant effect on e-commerce IS adoption behavior, and then Hypothesis 1a isn't supported. As to intrinsic motivation, the value of $t$ is 5.477, the 
Table 2. Model summary.

\begin{tabular}{ccccc}
\hline \multicolumn{5}{c}{ Model Summary } \\
\hline Model & $\mathrm{R}$ & R Square & Adjusted R Square & Std. Error of the Estimate \\
\hline 1 & $0.784^{\mathrm{a}}$ & 0.615 & 0.605 & 0.444 \\
\hline
\end{tabular}

apredictors: (Constant), annual household income, social support, propensity to informatization, social influence, intrinsic motivation, knowledge, extrinsic motivation, self-efficacy.

Table 3. Anova.

\begin{tabular}{ccccccc}
\hline \multicolumn{7}{c}{ Anova $^{\mathrm{a}}$} \\
Model & & Sum of Squares & $\mathrm{df}$ & Mean Square & F & Sig. \\
\hline \multirow{3}{*}{1} & Regression & 102.285 & 8 & 12.786 & 64.777 & $.000^{\mathrm{b}}$ \\
& Residual & 64.149 & 325 & 0.197 & & \\
& Total & 166.434 & 333 & & & \\
\hline
\end{tabular}

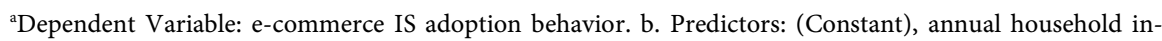
come, social support, propensity to informatization, social influence, intrinsic motivation, knowledge, extrinsic motivation, self-efficacy.

Table 4. Coefficients.

\begin{tabular}{|c|c|c|c|c|c|c|}
\hline \multicolumn{7}{|c|}{ Coefficients $^{\mathrm{a}}$} \\
\hline \multirow[b]{2}{*}{ Model } & & \multicolumn{2}{|c|}{$\begin{array}{l}\text { Unstandardized } \\
\text { Coefficients }\end{array}$} & \multirow{2}{*}{$\begin{array}{c}\text { Standardized } \\
\text { Coefficients }\end{array}$} & \multirow[b]{2}{*}{$\mathrm{t}$} & \multirow[b]{2}{*}{ Sig. } \\
\hline & & B & Std.Error & & & \\
\hline \multirow{9}{*}{1} & (Constant) & -0.738 & 0.162 & & -4.541 & 0.000 \\
\hline & Extrinsic motivation & -0.038 & 0.037 & -0.053 & -1.023 & 0.307 \\
\hline & Intrinsic motivation & 0.216 & 0.040 & 0.261 & 5.447 & 0.000 \\
\hline & Propensity to informatization & 0.223 & 0.032 & 0.364 & 7.044 & 0.000 \\
\hline & Social influence & 0.134 & 0.023 & 0.229 & 5.775 & 0.000 \\
\hline & Social support & 0.133 & 0.021 & 0.241 & 6.189 & 0.000 \\
\hline & Knowledge & 0.085 & 0.030 & 0.138 & 2.826 & 0.005 \\
\hline & Self-efficacy & 0.090 & 0.041 & 0.128 & 2.211 & 0.028 \\
\hline & Annual household income & 0.093 & 0.031 & 0.114 & 2.997 & 0.003 \\
\hline
\end{tabular}

${ }^{a}$ Dependent Variable : e-commerce IS adoption behavior.

value of sig. is less than 0.05 , which indicates that the intrinsic motivation dimension of habitus have a positive effect on e-commerce IS adoption behavior, that is, the stronger one's intrinsic motivation is, the more likely he will adopt and use the e-commerce IS all by himself. Hypothesis $1 \mathrm{~b}$ is supported. Similarly, according to Table 4, we can make the conclusion that hypothesis 1c to hypothesis 4 are also supported.

\section{Discussion}

\subsection{Discussion}

This study aims to understand the critical resources that contribute to the different adoption behaviors on e-commerce IS between the digital immigrants and 
investigate the relationship between digital immigrant's capitals, habitus and e-commerce IS adoption behavior. The statistical results support most of our hypotheses with regard to the relationship between digital immigrants' e-commerce IS adoption behaviors and their habitus, cultural capital, social capital, and economic capital. They also provide insight into the factors that are instrumental in promoting e-commerce IS adoption and usage among digital immigrant. Among these factors, by comparing the standardized coefficients of the variables, we conclude that four factors of them plays more important role in motivating e-commerce IS adoption, they are intrinsic motivation and propensity to informatization dimension of habitus, social support and social influence dimension of social capital.

Contrary to our hypothesis, extrinsic motivation doesn't significantly impact digital immigrants' e-commerce IS adoption behavior. The explanation for the lack of support maybe that most of the digital immigrants are middle-aged or above, they enjoy stable income and stable life, their quality of life has reached a certain height. Therefore, instead of external demand, they may be more concentrate about the internal needs. As a result, the extrinsic motivation is not significantly impact digital immigrants' e-commerce IS adoption behavior.

\subsection{Implications for Theory and Practice}

To begin with, this study makes a big contribution to the literature on Chinese digital immigrants and IS research, especially e-commerce IS research, as it is one of the first works that has attempted to operationalize the capital perspective to gain insight into this new social phenomenon. Our application of Bourdieu's capital perspective for studying e-commerce IS adoption has important implications for both digital immigrants and IS research.

As for practice implications, our findings suggest that electronic commercial enterprise should make efforts to gain and optimize various forms of capital digital immigrants, and transform their habitus on IS usage. Especially, focusing on intrinsic motivation, family, relatives, peers, and friends' influence, and support from acquaintances can stimulate this group's e-commerce IS adoption. As to intrinsic motivation, in advertising and publicity, electronic commercial enterprise should focus on the hedonic values of online shopping, which is critical for digital immigrants. E-commerce IS designers can also develop new functions aiming at optimize the digital immigrants' hedonic experience when using an e-commerce IS, such us personalized customization. In terms of social influence and social support, electronic commercial enterprise can take advantage of the younger generation, which are digital natives and family with the digital word. For example, managers can carry out promotional activities to stimulate the young to recommend his parents or help his parents to buy things online for one time.

\subsection{Limitation and Future Research}

As with all empirical research, this investigation has limitations. Firstly, for the 
convenience of data collection, we collected all the data online. It is worth noting that, sample bias may exist, which may weaken the generalizability of the findings. Therefore, some comparison studies or lab experiments, especially with different culture background or treating some demographic factors as the control or moderate variables, may shed more light on the generalizability of the results. In addition, most of the dimensions in our study is measured by respondents' perceptions, which are subjective data collected from one period of time. It is better to collect some objective data about the digital immigrant's actual participation. And future research should identify additional dimensions of these forms of capital that would be important for e-commerce IS adoption.

\section{Conclusion}

In sum, this study provides empirical evidence to understand the critical factors that impact digital immigrants' e-commerce IS adoption behavior. E-commercial enterprises should consider these factors, including habitus, social capital and cultural capital, to stimulate the digital immigrants. The results yield some suggestions and practical implications for the designers, managers, and information service staff.

\section{References}

[1] China Internet Network Information Center (2015) The 35th China Internet Development Statistics Report. China Internet, 8, 74-91.

[2] Hajli, M. (2012) An Integrated Model for E-Commerce Adoption at the Customer Level with the Impact of Social Commerce. International Journal of Information Science\& Management, 77-97.

[3] Hsieh, P.A., Rai, A. and Keil, M. (2011) Addressing Digital Inequality for the Socioeconomically Disadvantaged through Government Initiatives: Forms of Capital That Affect ICT Utilization. Information Systems Research, 22, 233-253. https://doi.org/10.1287/isre.1090.0256

[4] Prensky, M. (2001) Digital Natives, Digital Immigrants. Journal of Distance Education, 292, 1-6.

[5] Vodanovich, S., Sundaram, D. and Myers, M. (2010) Digital Natives and Ubiquitous Information Systems. Information Systems Research, 21, 711-723. https://doi.org/10.1287/isre.1100.0324

[6] Bourdieu, P. (1977) Outline of a Theory of Practice. Vol. 16, Cambridge University Press, New York.

[7] King, A. (2000) Thinking with Bourdieu against Bourdieu: A "Practical" Critique of the Habitus. Sociological Theory, 18, 417-433.

https://doi.org/10.1111/0735-2751.00109

[8] Bourgois, P. and Schonberg, J. (2007) Ethnic Dimensions of Habitus among Homeless Heroin Injectors. Ethnography, 8, 7-31.

https://doi.org/10.1177/1466138107076109

[9] Bourdieu, P. (1984) Distinction: A Social Critique of the Judgment of Taste. Journal of Experimental Social Psychology.

[10] Burt, R. (2001) Structural Holes versus Network Closure as Social Capital. In: Lin, N., Cook, K.S. and Burt, R.S., Eds., Social Capital: Theory and Research, Aldine de 
Gruyter.

[11] Bourdieu, P. (1990) The Logic of Practice. Stanford University Press, Stanford, CA.

[12] Kvasny, L. and Keil, M. (2006) The Challenges of Redressing the Digital Divide: A Tale of Two Us Cities. Information Systems Journal, 16, 23-53. https://doi.org/10.1111/j.1365-2575.2006.00207.x

[13] Henry, P. (2004) Hope, Hopelessness, and Coping: A Framework for Class-Distinctive Cognitive Capital. Psychology \& Marketing, 21, 375-403. https://doi.org/10.1002/mar.20010

[14] De Haan, J. (2004) A Multifaced Dynamic Model of the Digital Divide. IT Society, $1,66-88$.

[15] Davis, F.D., Bagozzi, R.P. and Warshaw, P.R. (1992) Extrinsic and Intrinsic Motivation to Use Computers in the Workplace. Journal of Applied Social Psychology, 22, 1111-1132. https://doi.org/10.1111/j.1559-1816.1992.tb00945.x

[16] Rogers, E.M. (2003) Diffusion of Innovation. 5th Edition, Free Press, New York.

[17] Hu, J., Huhmann, B.A. and Hyman, M.R. (2007) The Relationship between Task Complexity and Information Search: The Role of Self-Efficacy. Psychology \& Marketing, 24, 253-270. https://doi.org/10.1002/mar.20160

[18] Venkatesh, V. and Brown, S. (2001) A Longitudinal Investigation of Personal Computers in Homes: Adoption Determinants and Emerging Challenges. MIS Quarterly, 25, 71-102. https://doi.org/10.2307/3250959

Submit or recommend next manuscript to SCIRP and we will provide best service for you:

Accepting pre-submission inquiries through Email, Facebook, LinkedIn, Twitter, etc. A wide selection of journals (inclusive of 9 subjects, more than 200 journals)

Providing 24-hour high-quality service

User-friendly online submission system

Fair and swift peer-review system

Efficient typesetting and proofreading procedure

Display of the result of downloads and visits, as well as the number of cited articles

Maximum dissemination of your research work

Submit your manuscript at: http://papersubmission.scirp.org/

Or contact jss@scirp.org 